\title{
SUPERIOR LABIAL FRENECTOMY BY DOUBLE CLAMPING TECHNIQUE: CLINICAL CASE REPORT
}

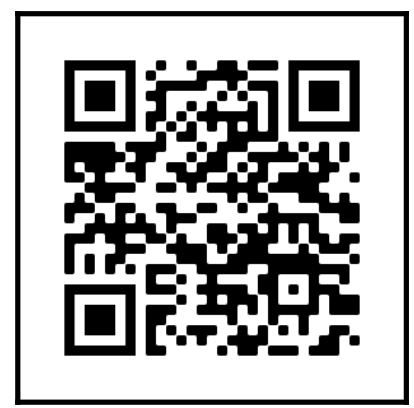

\section{Authors:}

Anna Carolina Andrade de Souza Vasconcelos

Student of the Dentistry school, Federal Fluminense University, Niterói, RJ, Brazil.

\section{Fernanda Britto de Melo Silva}

Specialist in Oral and Maxillofacial Surgery, Federal Fluminense University, Niterói, RJ, Brazil.

\section{Suelen Cristina Sartoretto}

Professor of Oral Surgery at the Iguaçu University, Nova Iguaçu, RJ, Brazil.

\section{Marcelo José Uzeda}

Professor of Oral Surgery at Federal Fluminense University, Niterói, RJ, Brazil.

Professor of Oral Surgery at the Iguaçu University, Nova Iguaçu, RJ, Brazil.

\section{Rodrigo Figueiredo de Brito Resende}

Professor of Oral Surgery at Federal Fluminense University, Niterói, RJ, Brazil.

Professor of Oral Surgery at Iguaçu University, Nova Iguaçu, RJ, Brazil.

Institution in which the study was carried out: Dentistry School, Federal Fluminense University, Niterói, RJ, Brazil.

\section{ABSTRACT}

The lip brake is a fold in the oral mucosa, originating in the upper lip and insertion in the alveolar mucosa. At birth, the labial frenum may be inserted in the palatal papilla. As the individual grows, he can migrate to a more upper region, featuring a normal lip curl. However, when it remains inserted in the papilla, it is a case of hypertrophic lip curl. When pathological, this structure can 
promote the formation of interincisal diastema, periodontal pocket, gingival retraction, aesthetic problems, difficulties in phonation and brushing. The objective of this article is to report a clinical case of upper lip frenectomy using the double clamping technique or Archer technique, performed at the Oral Minor Surgery clinic of the Dentistry School of the Federal Fluminense University, in a male patient, leucoderma, 23 years old, indicated by his orthodontist after recurrence of interincisal diastema. From the procedure performed, it can be concluded that the surgical intervention and the applied technique were effective in solving the reported clinical case.

Keywords: Diastema Lip Brake; Oral Surgery.

\section{INTRODUCTION}

The labial frenulum is a fold in the labial mucosa, triangular in shape, originating in the midline of the upper lip and insertion in the alveolar mucosa, more precisely in the line of the junction of the two maxillary bones. Histologically, it is formed by stratified keratinized squamous epithelium (in the area of the inserted gingiva) and non-keratinized (in the vestibular area). In addition, it has loose connective tissue, densely vascularized. (MACEDO, MP; DE CASTRO BS ET AL., 2012; ZIMERMANN, CO; MATSUURA, E ET AL., 2017)

Due to its histological constitution, its function is to limit the movement of the lip, promoting a stable labial midline and, consequently, hindering an excessive exposure of the gums. (ZIMERMANN, CO; MATSUURA, E ET AL., 2017; SILVA, C. L. S.; MELO, H. B. et al., 2020)

At birth, the labial frenum is inserted in the incisor papilla. However, with the development and growth of the individual, this structure migrates to a more apical region, thus characterizing a normal lip curl. However, if this migration does not occur and the brake remains inserted in the incisor papilla, it is considered an abnormal or hypertrophic lip brake. (MACEDO, MP; DE CASTRO BS ET AL., 2012)

It is extremely important that the dentist knows how to correctly diagnose the presence of a pathological lip brake. Thus, there are 3 clinical signs that assist in the diagnosis. They are: presence of interincisal diastema, insertion in the incisive papillae or in the gingival margin and ischemia of the incisive papillae 
when pulling the lip, through Graber's maneuver. (MACEDO, MP; DE CASTRO BS ET AL., 2012; ZIMERMANN, CO; MATSUURA, E ET AL., 2017; JOCHEM, G. A., 2018)

When pathological, the lip brake is capable of generating some problems for the patient, such as aesthetic problems, oral hygiene, phonation, restricting lip movements, presence of interincisal diastema, appearance of periodontal pouch and gingival retraction. (SILVA, HL; SILVA, JJ ET AL., 2018) Therefore, when diagnosed, surgical removal is indicated, through frenectomy.

Diastemas are dental spaces and commonly present in primary and mixed dentition. During development, the interincisal diastema tends to disappear, especially after the eruption of the lateral incisors and permanent upper canines. (ALMEIDA, RR; GARIB, DG ET AL., 1999; MALENTACCHI, A; GARRONE, VS ET AL., 2020).

The presence of a hypertrophic lip brake is one of the main factors for the occurrence of diastemas. (ZIMERMANN, CO; MATSUURA, E ET AL., 2017; SILVA, C. L. S.; MELO, HB ET AL., 2020) However, the persistence of the diastema has a multifactorial etiology. We can mention: an arch perimeter larger than the diameter of the permanent teeth, hereditary factors, congenital absence or reduced size of the permanent lateral incisors, pathological labial brake, supernumerary teeth, parafunctional habits, macroglossia, among others. (MALENTACCHI, A; GARRONE, VS ET AL., 2020)

In cases where there is no physiological correction of the diastema, the treatment for closing the space is done through orthodontics. In addition, in patients who were diagnosed with pathological lip brake, through its 3 clinical signs, the surgical technique of lip frenectomy becomes necessary. However, there are controversies in the literature on when to perform the excision of the labial frenum, whether before or after the ugly duckling phase and whether before, during or after orthodontic treatment. (MACEDO, MP; DE CASTRO BS ET AL., 2012; ZIMERMANN, CO; MATSUURA, E ET AL., 2017)

The objective of this study is to report a clinical case of upper lip frenectomy using the clamping technique or Archer technique, performed at the Faculty of Dentistry of Federal Fluminense University, in a 23-year-old male patient, presenting recurrence of interincisal diastema after the end of the period. orthodontic treatment, which made the surgical method indispensable for the preservation of the treatment already carried out. 


\section{ETHICAL CONSIDERATIONS}

This work followed the ethical standards of the Declaration of Helsinki of 1975, revised in 2000. The patient was advised about the free and informed consent term and the use of his images and data for scientific publication of the public institution Federal Fluminense University. This work was written based on the Clinical Case Report Guidelines (CARE, www.care-statement.org).

\section{CLINICAL CASE REPORT}

Male patient, leucoderma, 23 years old, without comorbidities, was referred to the Minor Oral Surgery clinic of the Dentistry School of Federal Fluminense University by his orthodontist after one year of completion of the case, with the indication of upper lip frenectomy. As the main complaint, the patient reported a recurrence of diastema compromising aesthetics. During clinical examination, during anamnesis, a history of previous orthodontic treatment was collected in order to correct interincisal diastema. The intraoral examination showed ischemia of the papilla when the lip was pulled, insertion of the brake in the incisor papilla and a small diastema between the central incisors. (FIGURE 1).

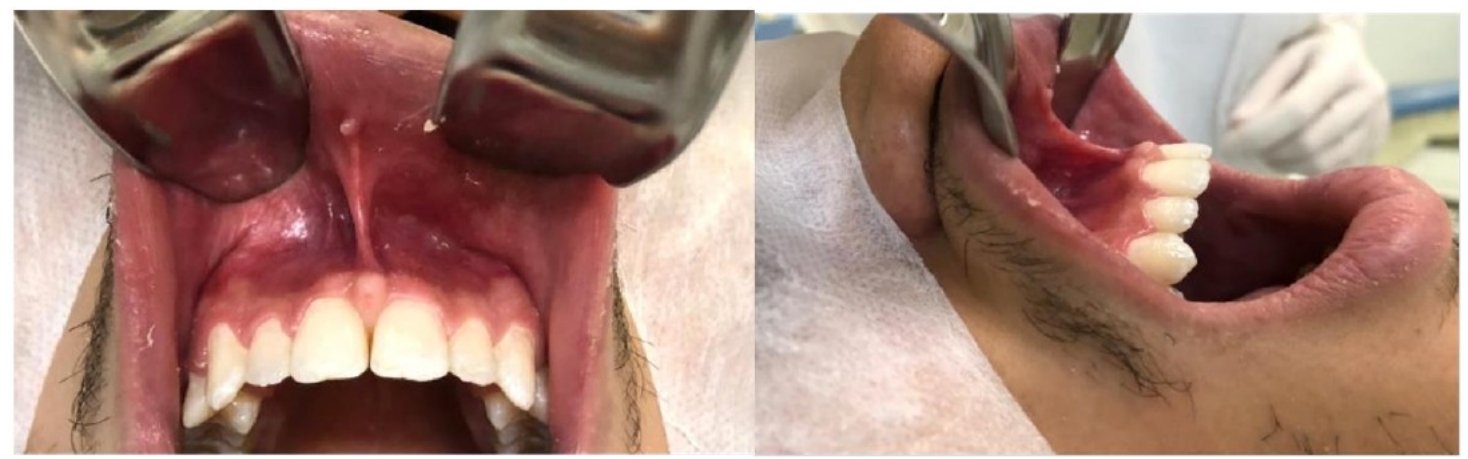

Figure 1: Front and side view showing clinical signs of the pathological upper lip brake.

As a treatment plan, it was proposed to the patient to perform the surgical procedure under local anesthesia in an outpatient setting, in order to preserve the result achieved by the orthodontic treatment already carried out and achieve the patient's aesthetic expectations. The surgical technique of choice was double clamping or also known as the Archer technique.

Initially, oral cavity antisepsis was performed using a mouthwash with $0.12 \%$ chlorhexidine digluconate (Periogard Colgate $®$, Rio de Janeiro, Rio de Janeiro, Brazil) for one minute and extraoral with the use of $4 \%$ chlorhexidine soap ( Riohex Rioquímica ${ }^{\circledR}$ Duque de Caxias, Rio de Janeiro, Brazil). Then, the 
sterile surgical field was affixed and the procedure was started with the use of topical anesthetic (Benzocaína $\AA$, DFL $®$ Rio de Janeiro - RJ, Brazil), where it was waited for 1 minute before performing a $16 \mathrm{~mm}$ penetration with a short $30 G$ needle (Unject $\AA$, DFL $®$ Rio de Janeiro - RJ, Brazil) for blocking the anterior superior alveolar nerves bilaterally, using $0.9 \mathrm{~mL}$ of $2 \%$ Lidocaine Hydrochloride with epinephrine 1: 100,000 (Alphacaine 100 - DFL® Rio de Janeiro - RJ Brazil) on each side and local palatal infiltration for local block of the palatal branches and aid in hemostasis of the region, using $0.5 \mathrm{~mL}$ of the same anesthetic, waiting about 10 minutes to start the procedure.

After confirmation of anesthesia, the two hemostatic forceps were positioned, according to the description of the Archer technique. The first hemostatic forceps was positioned as close as possible to the insertion of the brake in the inserted gum to the bottom of the vestibule. The second hemostatic forceps was positioned at the origin of the brake, in the mucosa of the upper lip and proceeded to the bottom of the vestibule (FIGURE 2).

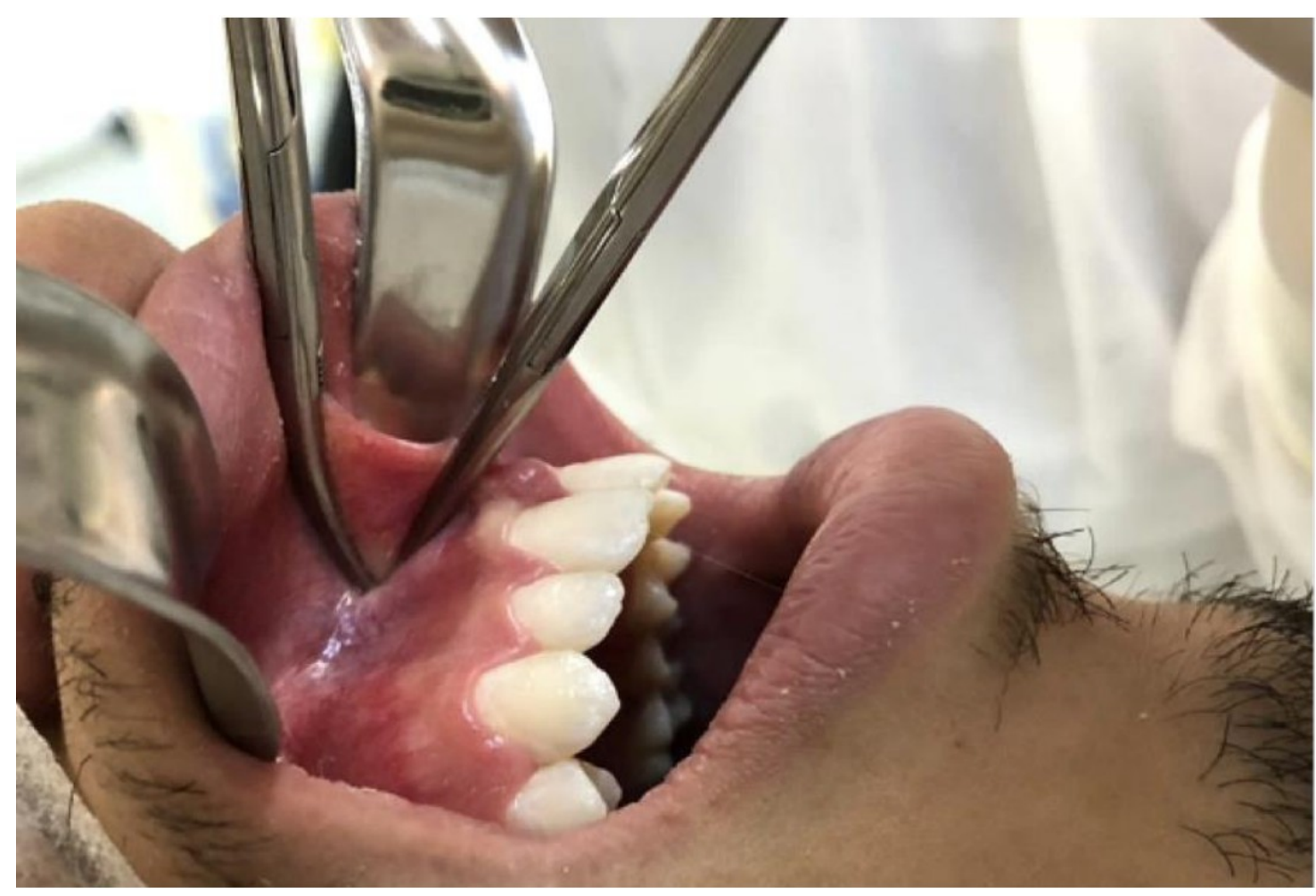

Figure 2: Positioning of hemostatic forceps.

After double clamping, anesthetic supplementation was performed on the labial brake, where this step aims to reduce bleeding due to the presence of a vasoconstrictor in the anesthetic solution (FIGURE 3). It is extremely important 
that this step is only performed with the brake already set, thus avoiding losing the anatomical contours, thus making it difficult to see the ends of the brake.

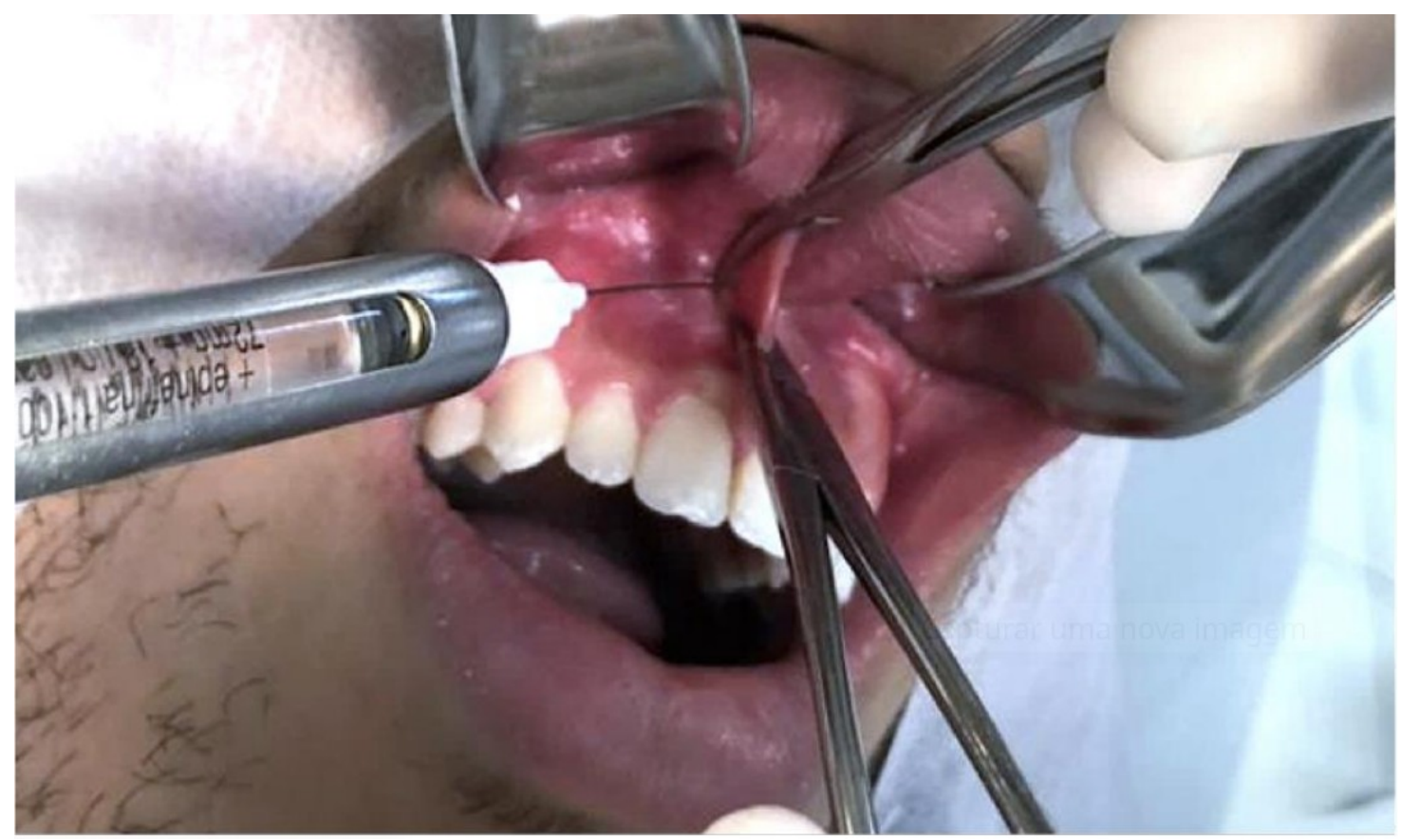

Figure 3: Injection of anesthetic solution into the brake after clamping.

Incisions can be made both from the outside and from the inside of the forceps. However, in this case, it was decided to perform them through the internal portion of the clamps, thus enabling greater protection of the structures adjacent to the brake and less intraoperative bleeding (FIGURE 4).

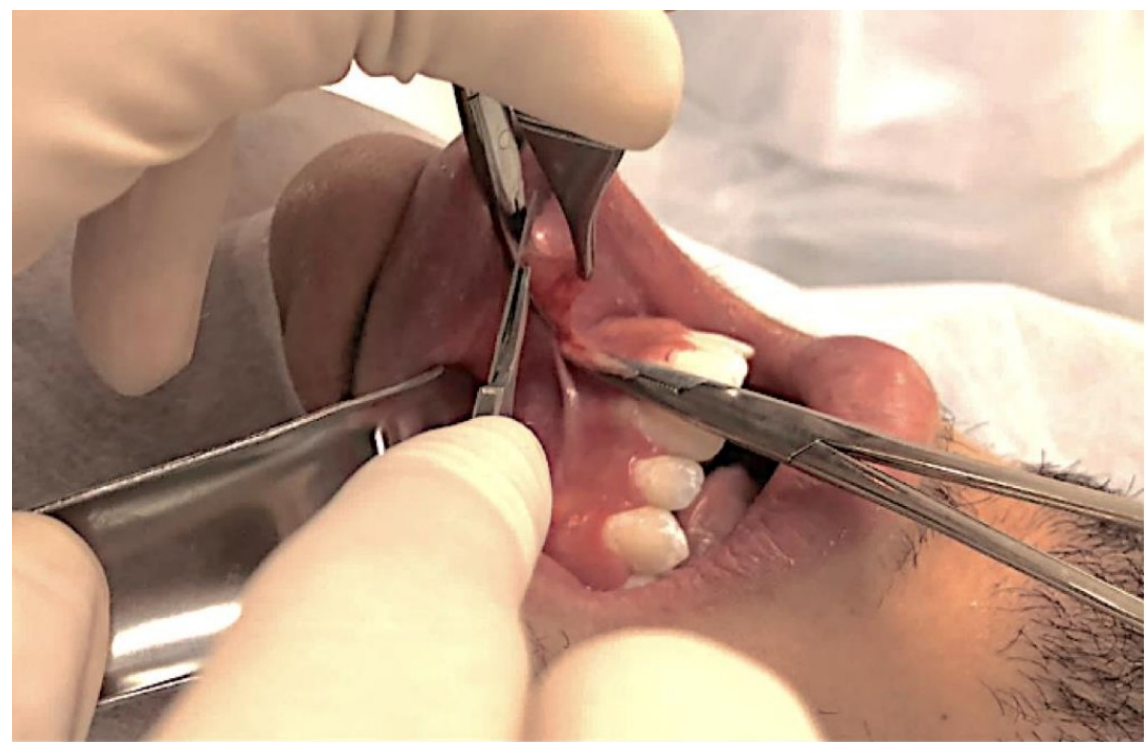

Figure 4: Scalpel incisions through the inner portion of the hemostatic forceps. 
With the incisions made, the hemostatic forceps were removed and the tissues were dislodged with iris scissors. This process is necessary in order for a reduction in tissue tension to occur and thus, tissue synthesis can be performed. In addition, it promotes the disinsertion of fibers and eliminates tissue residues from the brake.

After complete removal, the wound was constantly irrigated with $0.9 \%$ saline (Eurofarma® Rio de Janeiro - RJ Brazil), followed by a review of hemostasis. Tissue synthesis was then performed using 3-0 triangular needle silk thread (Ethicon® Somerville - New Jersey USA) only in the labial region. It is important that the first stitch of the suture is positioned between the inserted gingiva and the labial mucosa. This prevents further edema, in addition to providing greater stability in the tissue of the region. The wound in the inserted gingiva was not sutured, so that the healing occurred by second intention (FIGURE 5). There was no surgical complication during the trans - operative period.

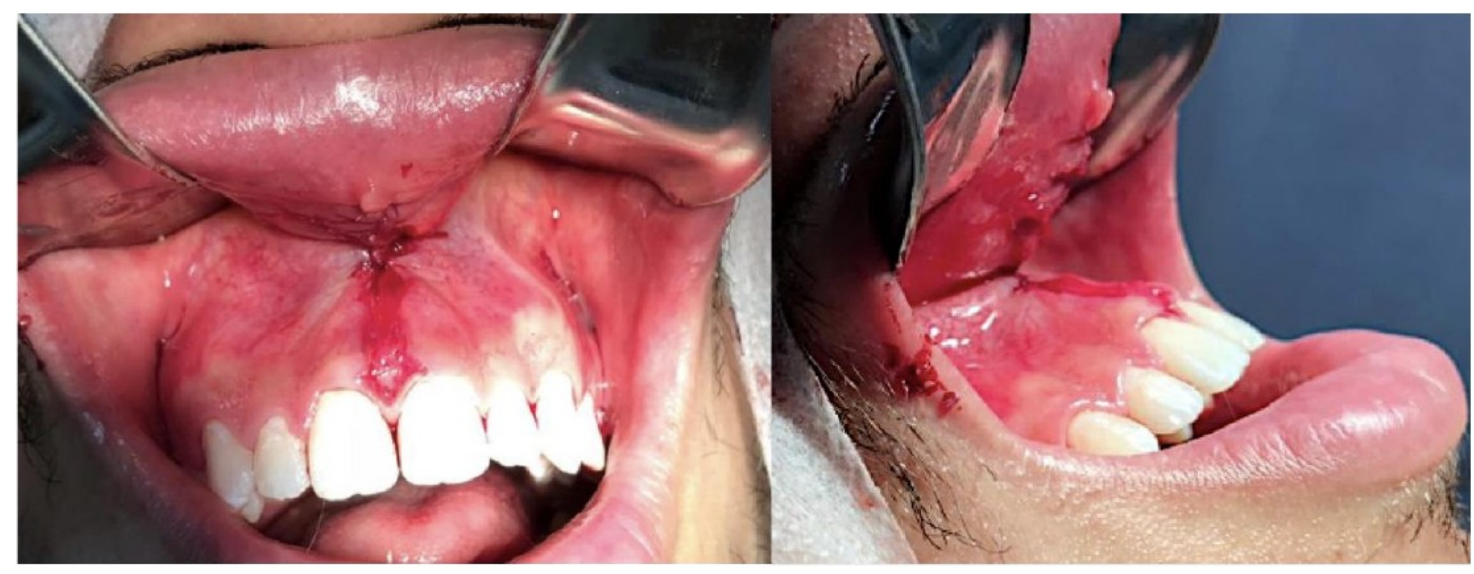

Figure 5: Front and side view of the area in the immediate postoperative period.

For the postoperative period, a non-steroidal anti-inflammatory was prescribed for forty-eight hours after the procedure, with Nimesulide $100 \mathrm{mg}$ every twelve hours and peripheral action analgesic to Dipyrone $1 \mathrm{~g}$ every six hours and postoperative instructions such as ice, liquid and pasty food, in addition to strict oral hygiene, thus avoiding possible local infection. The patient returned after the seven-day period to remove the suture at the UFF clinic, without the presence of infection and / or local inflammation.

He started his orthodontic treatment with his professional thirty days after the surgical procedure and after one year of postoperative surgical control, no recurrence of his diastema was seen and his orthodontic treatment ended with the removal of the orthodontic appliance and the use containment. 


\section{DISCUSSION}

According to the literature, the main difficulty of orthodontic treatment for closing the interincisal diastema is its post-treatment stability in cases where the brake is not excised. There are controversies about the ideal moment to perform the pathological brake frenectomy withthe aim of correcting the interincisal diastema, before or during the movement of the teeth. The eruption of the maxillary central incisors, maxillary lateral incisors and permanent maxillary canines should be minimally awaited, since diastemas are common during mixed dentition and tend to disappear progressively. However, it is known that this surgical procedure should not be performed after orthodontic treatment. (MACEDO, MP; DE CASTRO BS ET AL., 2012; ZIMERMANN, CO; MATSUURA, E ET AL., 2017; MALENTACCHI, A; GARRONE, VS ET AL., 2020)

Upper lip frenectomy associated with orthodontic treatment tends to be more advantageous. This happens because, during orthodontic movement, the tissue located between the upper central incisors is compressed. Therefore, the elastic and collagen fibers of this compressed tissue promote a reaction force that can result in the recurrence of the diastema. Thus, the pathological and thick lip brake can hinder or delay the movement of the teeth, and must be removed before or during orthodontic treatment. This is the recommended procedure to achieve the atrophy of the brake and prevent a possible recurrence. (MACEDO, MP; DE CASTRO BS ET AL., 2012)

In the reported clinical case, the patient did not undergo an upper lip frenectomy before or during his orthodontic treatment and again presented a diastema, one year after the removal of the fixed appliance. This situation reinforces even more what is reported in the literature, regarding the surgical removal of the pathological lip brake before or during orthodontic treatment.

There are several surgical techniques for performing upper lip frenectomy. In this clinical case, we opted for the double clamping technique or the Archer technique, since it has both hemostatic clamps as guides and thus, it is quick to perform and very safe, it simplifies the frenectomy, it presents a better control of transgender operative and allows the excision of a wide variety of lip brake morphologies. (SILVA, HL; SILVA, JJ ET AL., 2018) 


\section{CONCLUSIONS}

In the clinical case performed, the complete removal of the lip brake using the Archer Technique or Double Clamping Technique proved to be adequate, being a stable and predictable form in the long term. In addition, it allows a quick and safe execution.

\section{BIBLIOGRAPHIC REFERENCES}

1. MACEDO, M. P.; DE CASTRO, B. S. et al. Frenectomia labial superior em paciente portador de aparelho ortodôntico: relato de caso clínico. RFO, Passo Fundo, v. 17, n. 3, p. 332-335, 2012.

2. ZIMERMANN, C. O. et al. FRENECTOMIA LABIAL EM PACIENTE INFANTIL: RELATO DE DUAS TÉCNICAS CIRÚRGICAS. Revista UNINGÁ Review, [s. I.], v. 29, n. 2, p. 23-27, 2017.

3. SILVA, C. L. S.; MELO, H. B. et al. Frenectomia labial superior com laser cirúrgico de diodo: relato de caso clínico em paciente infantil. Research, Society and Development, [s. I.], v. 9, n. 11, 2020.

4. JOCHEM, G. A. FRENECTOMIA LABIAL SUPERIOR. 2018. Trabalho de Conclusão de Curso (Título de Cirurgião-Dentista) - Centro Universitário São Lucas, Porto Velho, 2018.

5. SILVA, H. L., SILVA, J. J. et al. Frenectomia: revisão de conceitos e técnicas cirúrgicas. SALUSVITA, Bauru, v. 37, n. 1, p. 139-150, 2018.

6. ALMEIDA, R. R.; GARIB, D. G. et al. Ortodontia Preventiva e Interceptora: Mito ou Realidade?. Rev Dental Press Ortodon Ortop Facial, [s. I.], v. 4, n. 6, p. 87-108, 1999.

7. MALENTACCHI, A.; GARRONE, V. S. et al. Redução de diastema após exodontia de dente supranumerário e frenectomia - um relato de caso. Odonto, [s. I.], v. 28, n. 55, p. 1-10, 2020. 